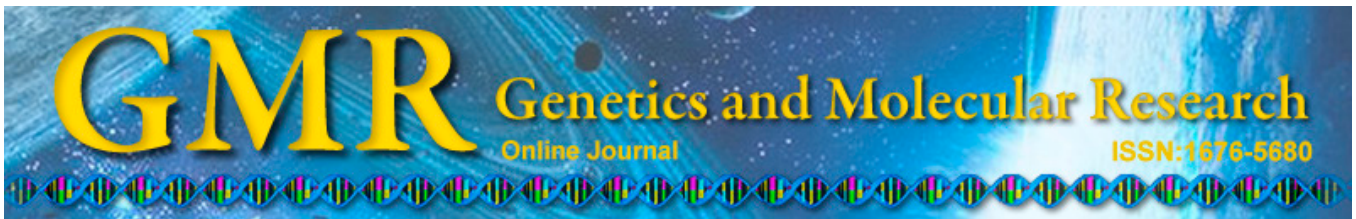

\title{
Microsatellite markers linked to the locus of the watermelon fruit stripe pattern
}

\author{
R.N.C.S. Gama ${ }^{1}$, C.A.F. Santos ${ }^{2}$, R.C.S. Dias ${ }^{2}$, J.C.S.F. Alves ${ }^{3}$ and \\ T.O. Nogueira ${ }^{4}$ \\ ${ }^{1}$ Programa de Pós-Graduação em Recursos Genéticos Vegetais, \\ Universidade Estadual de Feira de Santana, Feira de Santana, BA, Brasil \\ ${ }^{2}$ Embrapa Semiárido, Petrolina, PE, Brasil \\ ${ }^{3}$ Departamento de Tecnologia e Ciências Sociais, \\ Universidade do Estado da Bahia, Juazeiro, BA, Brasil \\ ${ }^{4}$ Departamento de Ciências Biológicas, Universidade de Pernambuco, \\ Petrolina, PE, Brasil \\ Corresponding author: R.N.C.S. Gama \\ E-mail: renata.natalia@hotmail.com
}

Genet. Mol. Res. 14 (1): 269-276 (2015)

Received July 25, 2014

Accepted November 12, 2014

Published January 16, 2015

DOI http://dx.doi.org/10.4238/2015.January.16.11

\begin{abstract}
Agronomic performance and external and internal appearance of watermelon (Citrullus lanatus) fruit are important traits that should be taken into consideration during the development of a new cultivar, as well as being the principal identification elements used by the consumer, which are based on the external appearance and quality of the fruit. Externally, the fruit can be characterized in terms of the shape, the color of the lower rind, and the presence of grooves and stripes, the stripes can be classified as clearly defined or diffuse. The objective of this study was to identify microsatellite markers linked to the stripe pattern of watermelon fruit to support watermelon improvement programs, with the selection of this characteristic in the plantlet stage. F1 and F2 populations, result of a cross between the cultivars BRS Opara (clearly defined stripes) and Pérola (diffuse stripes), were phenotyped for their fruit stripe pattern. The CTAB $2 \mathrm{X}$
\end{abstract}


protocol was used for DNA extraction and 116 microsatellite markers were examined in a group of F2 plants that had fruit with well-defined stripes and fruit with diffuse stripes. The microsatellite loci MCPI_05 and MCPI_16 exhibited a linkage to the stripe pattern at a distance of 1.5 and $1.8 \mathrm{cM}$, respectively, with LOD scores of 39.28 and 38.11 , respectively, which were located on chromosome six of the watermelon genome. These markers can be used in marker-assisted selection in watermelon improvement programs, by various research institutions.

Key words: Citrullus lanatus; Fruit external pattern; SSR; Assisted selection

\section{INTRODUCTION}

The watermelon (Citrullus lanatus) is a member of the Cucurbitaceae, and is cultivated all over the world. There are various cultivars of this species, which differ from one another in terms of the external pattern of the fruit, the color of the pulp, the level of soluble solids, the yield, resistance to pests and diseases, and precocity, among other desirable agronomic traits. A summary of these morphological traits is provided by Dias et al. (2010) and Gama et al. (2013).

During the development of a new cultivar, it is necessary to consider the possible clients: producers, industry, and consumers (Borém and Miranda, 2013). According to Dias et al. (2010), the cultivar Crimson Sweet (and similar types), which is American in origin and has a clearly defined stripe pattern, is the most cultivated in Brazil, and accounts for over $90 \%$ of the consumer market. When selecting a cultivar for planting, the following should be taken into consideration: the fruit that is preferred by the consumer market, its tolerance of transport, the adaptation of the cultivar to the region, and its tolerance to disease and to physiological disorders. Therefore, genetic improvement programs should have various goals, including resistance to disease and pests, increased yield, and the external and internal appearance of the fruit, since appearance is the consumer's method of identifying the cultivar.

According to morphological descriptions of watermelons (Brazilian Ministry for Agriculture), the external pattern of watermelon fruit can be characterized in terms of the shape of the fruit, the color of the lower rind, the presence of grooves, the presence of stripes (welldefined or diffuse), the intensity of the stripe coloration, and the width of the stripes. The internal pattern can be characterized in terms of the thickness of the pericarp, coloration, and the firmness of the flesh (Brasil, 2009).

Classic improvement techniques for the selection of the watermelon fruit pattern can only be conducted during the fructification stage or during harvest, 40 and 80 days after sowing, respectively. Biotechnological techniques, such as microsatellite markers, make it possible to select individuals based on their genotype, independently of biotic or abiotic factors, and at any developmental stage of the plant. In this way, the identification of molecular markers that are linked to phenotypic traits, such as the stripe pattern of watermelon fruits, enables selection of the desired external pattern of the fruit still in the seedling stage, as well as a better understanding of the inheritance of the trait between progenies and a reduction in the number of individuals that have to be examined in the field (Bhering et al., 2009). Marker-assisted selection (MAS) tends to speed up improvement programs, because selection can be conducted during the initial stages of plant development, which is of fundamental importance for the development of new 
cultivars (Demore, 2008). Various molecular markers that are associated with different phenotypic traits permit MAS, and can add various traits of interest to a new cultivar.

Microsatellite markers, also known as simple sequence repeats (SSRs), consist of units of approximately one to six nucleotides repeated in tandem (Oliveira et al., 2006; Caixeta et al., 2009). They have been developed for various cultivated plant species and are quickly replacing other marker types in various types of genetic studies, because of their reproducibility and technical simplicity, the small amount of DNA that is required, their low cost, their great resolving power, and their high levels of polymorphism (Caixeta et al., 2009). Gama et al. (2013) used 36 molecular markers to characterize 17 watermelon cultivars, and observed the formation of two groups, one that contained cultivars that exhibited a diffuse stripe pattern, and one that contained cultivars that exhibited a well-defined stripe pattern.

The authors also found that for the markers MCPI-05 and MCPI-16, all the cultivars that had well-defined stripe patterns had the same allelic pattern.

The objective of this study was to identify microsatellite markers linked to the stripe pattern of watermelon fruit to support watermelon improvement programs, with the selection of this characteristic in the plantlet stage.

\section{MATERIAL AND METHODS}

\section{Plant material}

Crosses were made by controlled hand-pollination (CHP), as described by Dias et al. (2001), between two watermelon cultivars that had different stripe patterns on their fruit: the cv. BRS Opara (well-defined stripes) and the cv. Pérola (diffuse stripes), to obtain the F1 population. Samples of young leaves were collected from each parent and stored in a freezer at $-80^{\circ} \mathrm{C}$ until DNA extraction. After harvesting, the fruits from this cross were characterized, and the seeds were washed and dried. Seeds (F1) of one of these fruits were sown in polystyrene trays and kept in a greenhouse for 12 days. At the beginning of seedling development, leaf samples of the F1 were collected for later DNA extraction and confirmation of hybridization by polymerase chain reaction (PCR) analysis, using microsatellite markers.

Seedlings of the F1 population were transplanted to the Experimental Field of Embrapa Semiárido, Petrolina, PE, Brazil. During the flowering stage, the autofecundation of these plants was conducted by CHP to obtain the F2 population. After harvesting, the fruits were characterized and the seeds were washed and dried.

A final field experiment was carried out, in which fruit from the parents of the F1 and F2 populations were characterized in terms of their stripe patterns (well-defined or diffuse stripes). One-hundred plants of the F1 population and 200 plants of the F2 population (the seeds used were collected from a single fruit), as well as thirty plants of each parent, were examined. During the initial seedling development stage, young and mature leaf samples were collected from the $\mathrm{F} 2$ population and stored in a freezer at $-80^{\circ} \mathrm{C}$ until DNA extraction. During this stage, no leaf samples were collected from the parents or the F1 population, because this DNA had been extracted earlier.

\section{DNA extraction and microsatellite analyses of the F1s}

DNA extraction of the leaves was conducted using the Doyle and Doyle (1990) 
CTAB $2 X$ protocol, modified to 7500 and $10,000 \mathrm{rpm}$ at the first and the second centrifugations, respectively, and $2 \%$ beta-mercaptoethanol and incubation at $60^{\circ} \mathrm{C}$ for $30 \mathrm{~min}$, for all the samples. The DNA was resuspended in a Tris-EDTA buffer and treated with RNAse to remove co-isolated RNAs. The quantification, and an integrity analysis, of the DNA were carried out on $0.8 \%$ agarose gel, and the samples were subsequently stored in a freezer at $-20^{\circ} \mathrm{C}$.

Five microsatellite markers were used (MCPI 04, MCPI_05, MCPI_11, MCPI 16, and MCPI_26) and were developed for the watermelon by Joobeur et al. (2006), for the inclusion of paternity and confirmation of the hybrids. These SSRs were selected based on the study by Gama et al. (2013), because they exhibited PCR products of different sizes for these cultivars. The PCR was conducted by following the protocol of Joobeur et al. (2004), with some modifications: the total volume of $12 \mu \mathrm{L}$ contained $50 \mathrm{ng}$ DNA, $5 \mu \mathrm{M}$ of each primer, $0.1 \mathrm{mM} \mathrm{dNTP}, 1.5 \mathrm{mM} \mathrm{MgCl}{ }_{2}, 1 \mathrm{X}$ PCR buffer, and $0.75 \mathrm{U}$ Taq polymerase DNA enzyme. The programming of the thermocycler for the amplifications was as follows: an initial cycle of $94^{\circ} \mathrm{C}$ for $2 \mathrm{~min}$, followed by 30 cycles at $94^{\circ} \mathrm{C}$ for $15 \mathrm{~s}$, at $56^{\circ} \mathrm{C}$ for $30 \mathrm{~s}$, and at $72^{\circ} \mathrm{C}$ for $2 \mathrm{~min}$, and a final cycle at $72^{\circ} \mathrm{C}$ for $30 \mathrm{~min}$. Half of the volume from the reaction and $98 \%$ formamide denaturation buffer (10 mM EDTA, $\mathrm{pH} 8.0,1 \mathrm{mg} / \mathrm{mL}$ xylene cyanol, and $1 \mathrm{mg} / \mathrm{mL}$ bromophenol blue) was added to the PCR solution, followed by complete denaturation at $94^{\circ} \mathrm{C}$ for $5 \mathrm{~min}$ in a thermocycler, then was immediately put on ice until use on a polyacrylamide gel. The amplification products were separated on $6 \%$ polyacrylamide gel, prepared on a glass plate of the sandwich type, with a capacity for sixty holes. A pre-run of $30 \mathrm{~min}$ at $35 \mathrm{~W}$ was conducted before adding the PCR samples. Two-and-a-half microliters of the denatured PCR on the $6 \%$ polyacrylamide gel was subjected to an electrophoresis current that was maintained for approximately $3 \mathrm{~h}$, with a constant potential of $45 \mathrm{~W}$. A 50-bp molecular-weight ladder (Fermentas) was charged at the lateral extremity of each gel. The gels were stained with silver nitrate, in accordance with the procedure described by Creste et al. (2001). To confirm that the obtained result of the cross between the cultivars was from F1 plants, and was free of contamination, the hybrids were examined to ascertain whether they only exhibited the allelic patterns of the parents.

\section{Phenotyping for the stripe patterns of watermelon fruit in the F1 and F2 populations and the parents}

Harvesting was conducted manually, 75 days after sowing. The fruits were identified by the plant number, and taken to a barn where they were characterized in terms of morphological descriptors for the watermelon. The number of fruits with well-defined or diffuse stripe patterns was recorded.

\section{Genotyping the F2 population for stripe patterns on the fruit using microsatellite markers}

A total of 116 microsatellite markers developed for the watermelon were analyzed, seven of which were developed by Jarret et al. (1996), 18 by Guerra-Sanz (2002), 36 by Joobeur et al. (2006), and 55 by Ren et al. (2012), in order to select those primers that exhibited PCR products of different sizes among the parents. These were ten used to analyze five individual fruits with well-defined stripe patterns and five with diffuse stripe patterns from the F2 
population, to identify alleles that were present in the individuals with well-defined stripe patterns and absent in the individuals with diffuse stripe patterns, and vice-versa. After verifying this characteristic with these thirty individuals, the selected primers were used to genotype the 200 individuals of the F2 population. The methodology used for DNA extraction, PCR, and use of microsatellite markers and revelation of the polyacrylamide gels was the same as was previously described for the F1 DNA extraction and microsatellite analyses.

\section{Statistical analyses and identification of the chromosomal region of the stripe patterns of watermelon fruit}

The data were annotated for the presence (1) or absence (0) of alleles. The data obtained by microsatellite markers and a visual evaluation of the fruit with well-defined or diffuse stripes were subjected to a chi-squared test with the significance set at $\mathrm{P}<0.05$, to verify the expected Mendelian segregation pattern of 3:1 in the F2 population. The linkage analyses were performed using the JoinMap (version 2.0) program (Stam and Van Ooijen, 1995), and the values obtained by the recombination frequencies were converted to maps of genetic distance (in centimorgans) using the Kosambi function (Kosambi, 1944). A BLAST of the primer sequence and its PCR products was performed on the genome of this species, in relation to the stripe patterns on its fruit.

\section{RESULTS}

The five microsatellite markers (MCPI_04, MCPI_05, MCPI_11, MCPI_16, and MCPI_26) used to confirm hybridization were capable of discriminating the F1 population from its parents: individuals of the F1 population only exhibited the alleles of the feminine genitor (BRS Opara) and of the masculine genitor (Pérola).

During the phenotyping of the F1 and F2 populations and the parents for the external stripe patterns on the fruit, it was found that the parents were homozygous for this characteristic, because $100 \%$ of the examined fruits of cv. BRS Opara had well-defined stripe patterns and $100 \%$ of the fruits of cv. Pérola exhibited diffuse stripe patterns. In the F1 population, $100 \%$ of the fruits had well-defined stripes; in the F2 population, $150(75 \%)$ of the fruits had well-defined stripes and $50(25 \%)$ had diffuse stripe patterns. The observed values of the F2 population are equal to those that were expected for a monogenic and dominant character. The study of inheritance genetics carried out on the F2 population indicated that the presence of well-defined stripes is conditioned by a dominant gene, which segregates at a ratio of 3:1.

Only 12 of the 116 microsatellite markers examined were polymorphic in the parents of the population studied. During the analysis of ten individuals from the F2 population, only two primer pairs exhibited the expected allelic pattern, with the presence of an allele in the fruits with a well-defined stripe pattern and an absence of an allele in the fruits with a diffuse stripe pattern. The primer pairs were as follows: MCPI_05 (ATTTCTGGCCCCAGTGTAAG/GA ACAACGCAACCACGTATG) and MCPI 16 (TGCTCAATCCACCCTTTCTC/AAAAACA GCAACTCTCCCATC), developed by Joobeur et al. (2006). During the genotyping of the 200 individuals of the F2 population, the markers revealed the presence of an allele in the fruits with well-defined stripe patterns and the absence of an allele in the fruits with a diffuse stripe pattern (Figure 1). 


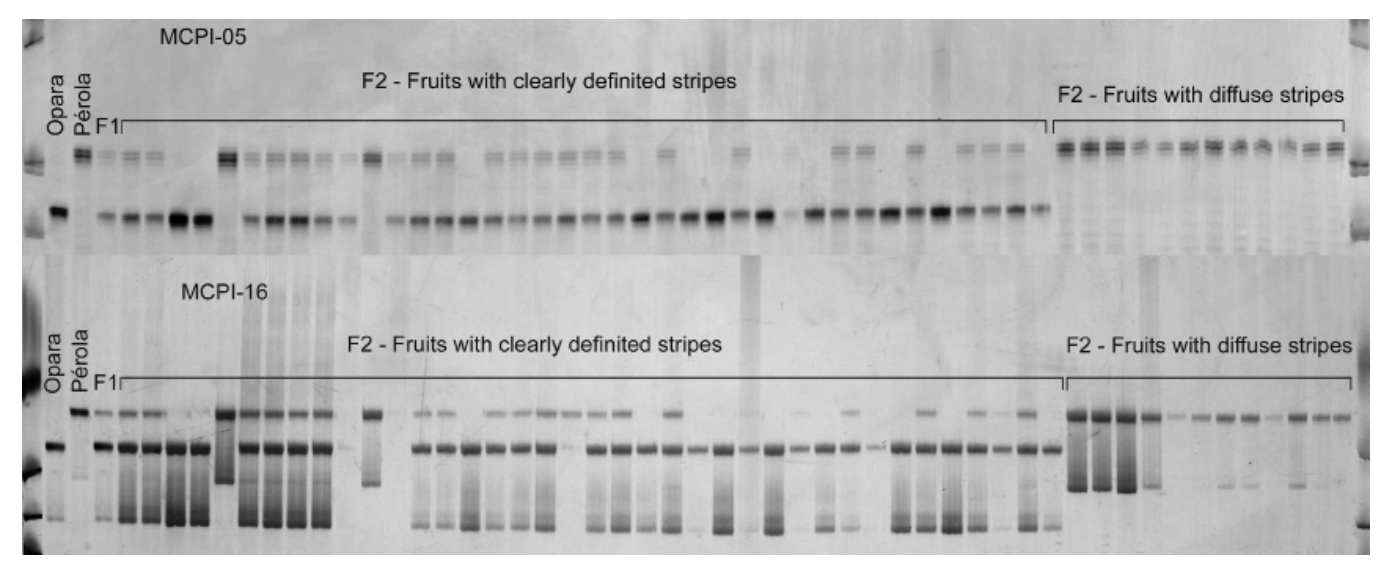

Figure 1. Allelic patterns of the watermelon cultivars BRS Opara (fruits with well-defined stripes) and Pérola (fruits with diffuse stripes) of F1 and of 50 individuals from the F2 population (38 with well-defined stripes and 12 with diffuse stripes), using two microsatellite markers (MCPI_05 and MCPI_16) that are associated with the stripe pattern of watermelon fruit.

The linkage analyses performed using JoinMap 2.0 revealed that the microsatellites MCPI_05 and MCPI_16 are linked to the gene responsible for the stripe pattern of watermelon fruit at a distance of 1.5 and $1.81 \mathrm{cM}$, respectively, with LOD scores of 39.28 and 38.11 , respectively. The BLAST search of the two primer pair sequences and their PCR products performed on the watermelon genome, revealed that the gene related to the stripe patterns on watermelon fruit is located on chromosome six, and that the two markers in question are very close to each other, and to some genes predicted by Guo et al. (2013).

\section{DISCUSSION}

The results for obtaining the F1 and F2 populations indicate that the PMC method described by Dias et al. (2001) is effective in obtaining watermelon crosses in which the genitors have to be controlled and are free from pollen contamination by other genotypes. The microsatellite markers MCPI_04, MCPI_05, MCPI_11, MCPI_16, and MCPI_26 could be used as identification tools in parentage analysis of watermelon hybrids, in crosses among the cultivars 'BRS Opara' and 'Pérola'. Furthermore, such markers could also be used to distinguish 'BRS Opara' from the hybrid obtained in this study, because both are mildew resistant and have a well-defined stripe pattern. In addition to exhibiting a slightly different green skin tonality, it is also important to point out that the hybrids cannot possibly be identified with absolute certainty by using only morphological descriptors, because skin coloration can be influenced by environmental factors. Using molecular markers, the selection of the external pattern of the fruit can even be conducted before the fructification stage, at the plantlet stage. The frequent use of the marker in genetic studies, including paternity tests, is due to the fact that it is co-dominant, multiallelic, highly reproducible, and has a high resolution (Varshney et al., 2005; Oliveira et al., 2006).

The results obtained from the phenotyping of the $\mathrm{F} 1$ and $\mathrm{F} 2$ populations and the parents for the stripe pattern followed the Mendelian segregation of 3:1 (well-defined stripes:diffuse stripes), with a dominant gene that confers the well-defined stripe pattern. Therefore, it can be concluded that the heredity of this characteristic is monogenic and dominant. From the 
genotyping of the F2 population using the microsatellite markers MCPI_05 and MCPI_16, it was revealed that these are intimately linked to the locus that confers the characteristic stripe patterns on watermelon fruit. These markers could be used in MAS to select this characteristic in watermelons still in the plantlet stage. It is not necessary to wait until the fructification stage to select the pattern of the desired fruit, and there is the advantage of being able to identify homozygous and heterozygous individuals for this characteristic. Such considerations would save time, space, and money, because they allow the breeder to include only those plants that show the desired characteristic for an improvement program.

Few studies have used molecular markers in relation to phenotypic traits in the watermelon. Lin et al. (2009) identified a random amplified polymorphic DNA (RAPD) marker that is linked to resistance to Fusarium oxysporum f. sp niveum, and based on this, a sequenced characterized amplified region (SCAR) marker was developed, which, according to the authors, is able to quickly and accurately identify genotypes of watermelon that are resistant and susceptible to Fusarium. Wechter et al. (2008) studied the genetic expression of the watermelon fruit during maturation, in three stages: green pulp (start of development), pink pulp (start of maturation), and red pulp (mature fruit) using microarrays, and identified genes that are possibly related to the maturation events of the fruit. Prothro et al. (2012) identified a quantitative trait locus (QTL), named M-QTL, in the linkage group (LG 2) as a candidate for MAS for watermelon seed size.

Studies involving molecular markers associated with phenotypic traits have also been developed in other members of the Cucurbitaceae, such as melon and cucumber. Some studies have associated molecular markers with phenotypic traits, both for resistance to disease and for various fruit traits. Liu et al. (2010) analyzed 700 combinations of sequence-related amplified polymorphism (SRAP) primers, and identified a marker linked to the gene that confers resistance to Podosphaera xanthii, at a distance of $3.9 \mathrm{cM}$. Liu et al. (2010) cloned, sequenced, and converted this marker into SCAR. The authors stated that this marker can be used in MAS in the development of watermelon cultivars, in order to achieve resistance to P. xanthii. Meng et al. (2012) analyzed 130 plants of an F2 population from a cross of two cucumber genotypes, B-2-2 (long-fruit shape) and Y-3 (round-fruit shape), and identified SRAP markers that are linked to cucumber shape. Napier et al. (2009) identified a RAPD marker and an orange pulp-coloration marker in watermelon fruit that are linked to the QTLs for the high level of beta-carotene.

Studies that associate phenotypic traits with molecular markers in the watermelon are at an early stage. Following the characterization of the genome of this species by Guo et al. (2013), various other traits of interest could be associated with molecular markers, such as the soluble solid content, skin and pulp color, yield, acidity, precocity, and resistance to disease and pests, among others. The microsatellite markers MCPI_05 and MCPI_16 that were identified in this study as being linked to the stripe pattern in watermelon fruit can be used in MAS for the development of cultivars of this crop. Furthermore, the identification of the chromosome on which these markers are located will allow a closer study of the genes that are found in the proximity of these markers, which may be related to the stripe pattern of watermelon fruit.

\section{ACKNOWLEDGMENTS}

The authors wish to thank CAPES for a scholarship for the first author and to Embrapa Semiárido for supporting the research activities. 


\section{REFERENCES}

Bhering LL, Pinto CABP, Benites, FRG, Leite ME, et al. (2009). Seleção assistida por marcadores para teor de matéria seca e açúcares redutores em tubérculos de batata. Cienc. Rural 39: 8-44.

Borém A and Miranda GV (2013). Melhoramento de Plantas. 6th edn. Universidade Federal de Viçosa, Viçosa.

Brasil (2009). Rules to Apply Distinguibility, Homogenity and Stability Descriptors for Watermelon Cultivars. Diário Oficial da República Federativa do Brasil, Brasília, DF, 30 Junho 2009. Section 1.

Caixeta ET, Oliveira ACB de, Brito GG de and Sakuyama NS (2009). Tipos de Marcadores Moleculares. In: Marcadores Moleculares (Borém A and Caixeta ET, eds.). UFV, Viçosa, 11-94.

Creste S, Tulmann Neto A and Figueira A (2001). Detection of single sequence repeat polymorphisms in denaturing polyacrylamide sequencing gels by silver staining. Plant Mol. Biol. Rep. 19: 299-306.

Demore P dos S (2008). Seleção Assistida por Marcadores Moleculares Microssatélites para Resistência ao Oídio em Soja. Master's thesis, UNESP, São José do Rio Preto.

Dias R de CS, Costa ND, Queiróz, MA de and Faria CMB de (2001). Cultura da Melancia. Embrapa Semiárido, Petrolina, 20.

Dias R de CS, Barbosa GS, Souza FF, Queiróz MA de, et al. (2010). Cultivares. In: Sistema de Produção de Melancia (Dias R de CS, Resende GM de and Costa ND, eds.). Petrolina: Embrapa Semiárido, 2010. (Embrapa Semiárido. Sistemas de Produção, 6). Available at [http://sistemasdeproducao.cnptia.embrapa.br/FontesHTML]. Melancia/ SistemaProducaoMelancia/cultivares.htm. Accessed April 23, 2014.

Doyle JJ and Doyle JL (1990). Isolation of plant DNA from fresh tissue. Focus 12: 13-15.

Gama RNCS, Santos CAF, Dias R de CS and Souza F de F (2013). Molecular characterization of watermelon cultivars using microsatellite markers. Hort. Bras. 31: 522-527.

Guerra-Sanz JM (2002). Citrullus simple sequence repeats markers from sequence databases. Mol. Ecol. Notes 2: 223-225.

Guo S, Zhang J, Sun H, Salse J, et al. (2013). The draft genome of watermelon (Citrullus lanatus) and resequencing of 20 diverse accessions. Nat. Genet. 45: 51-60.

Jarret RL, Merrick LC, Holms T, Evans J, et al. (1996). Simple sequence repeats in watermelon (Citrullus lanatus (Thunb.) Matsum. \& Nakai). Genome 40: 433-441.

Joobeur T, King JJ, Nolin SJ, Thomas CE, et al. (2004). The Fusarium wilt resistance locus Fom-2 of melon contains a single resistance gene with complex features. Plant J. 39: 283-297.

Joobeur T, Gusmini, G, Zhang A, Levi A, et al. (2006). Construction of a watermelon BAC library and identification of SSRs anchored to melon or Arabidopsis genomes. Theor. Appl. Genet. 112: 1553-562.

Kosambi DD (1944). The estimation of map distance from recombination values. Ann. Eugen. 12: 172-175.

Lin Y-H, Chen K-S, Liou T-D, Huang J-W, et al. (2009). Development of a molecular method for rapid differentiation of watermelon lines resistant to Fusarium oxysporum f. sp. niveum. Bot. Stud. 50: 273-280.

Liu L, Chen Y, Su Z, Zhang H, et al. (2010). A sequence-amplified characterized region marker for a single, dominant gene in melon PI 134198 that confers resistance to a unique race of Podosphaera xanthii in China. HortScience 45: 1407-1410.

Meng H, Chen S, Cheng Z, Chai D, et al. (2012). SRAP markers for fruit shape in cucumber. Pak. J. Bot., 44: 1381-1384.

Napier AB, Park SO, Hwang HY and Crosby KM (2009). Identification and confirmation of molecular markers and orange flesh color associated with quantitative trait loci for beta-carotene in musk melon. ISHS Acta Hort. 841: 585-588. Available at [http://www.actahort.org/books/841/841_89.htm]. Accessed April 23, 2014.

Oliveira EJ, Pádua JG, Zucchi MI, Vencovsky R, et al. (2006). Origin, evolution and genome distribution of microsatellites. Genet. Mol. Biol. 29: 294-307.

Prothro J, Sandlin K, Abdel-Haleem H, Bachlava E, et al. (2012). Main and epistatic quantitative trait loci associated with seed size in watermelon. J. Am. Soc. Hort. Sci. 137: 452-457.

Ren Y, Zhao H, Kou Q, Jiang J, et al. (2012). A high resolution genetic map anchoring scaffolds of the sequenced watermelon genome. Plos One 7: 1-10. e29453.

Stam P and Van Ooijen JW (1995). JoinMap Version 2.0: Software for the Calculation of Genetic Maps. CPRO-DLO, Wageningen.

Varshney RK, Garner A and Sorells ME (2005). Genic microsatellite markers in plants: features and applications. Trends Biotechnol. 23: 48-63.

Wechter WP, Levi A, Harris KR, Davis AR, et al. (2008). Gene expression in developing watermelon fruit. BMC Genomics 9: 275 . 